\title{
Design and Analysis of a Hyperspectral Microwave Receiver Subsystem
}

W. Blackwell, C. Galbraith, T. Hancock, R. Leslie, I. Osaretin, M. Shields, P. Racette (NASA GSFC), L. Hilliard (NASA GSFC)

IGARSS 2012 


\section{Outline}

- Project summary, key objectives, and roles/responsibilities

- $\mathrm{RF}$ receiver electronics and scan head

- IF processor module

- Next steps 


\section{Project Summary and Key Objectives}

- Hyperspectral microwave (HM) sounding has been proposed to achieve unprecedented performance

- HM operation is achieved using multiple banks of RF spectrometers with large aggregate bandwidth

- A principal challenge is Size/Weight/Power scaling

- Objectives of this work:

- Demonstrate ultra-compact $\left(100 \mathrm{~cm}^{3}\right)$ 52-channel IF processor (enabler)

- Demonstrate a hyperspectral microwave receiver subsystem

- Deliver a flight-ready system to validate $\mathrm{HM}$ sounding
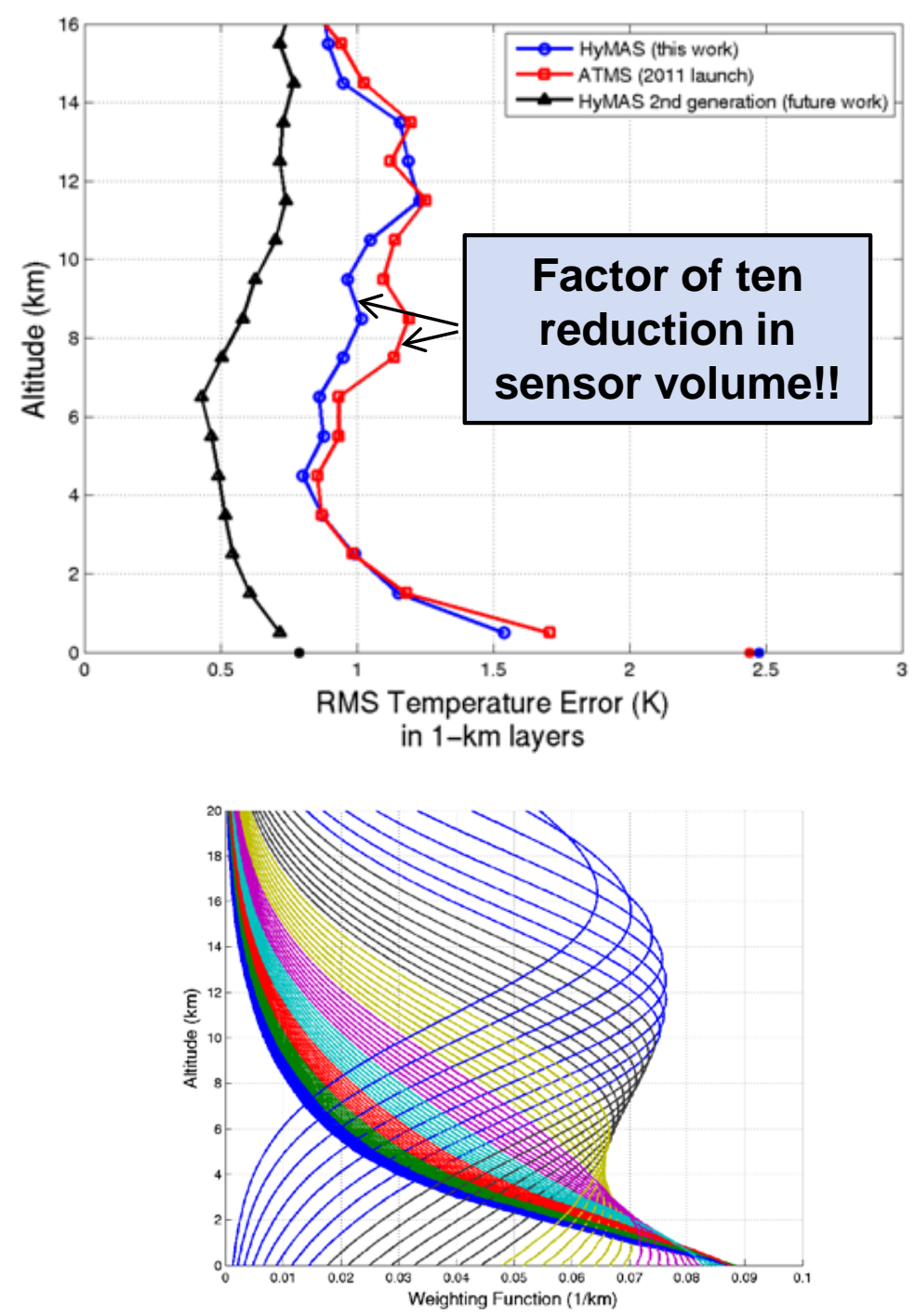


\section{HyMAS System Components Roles and Responsibilities}

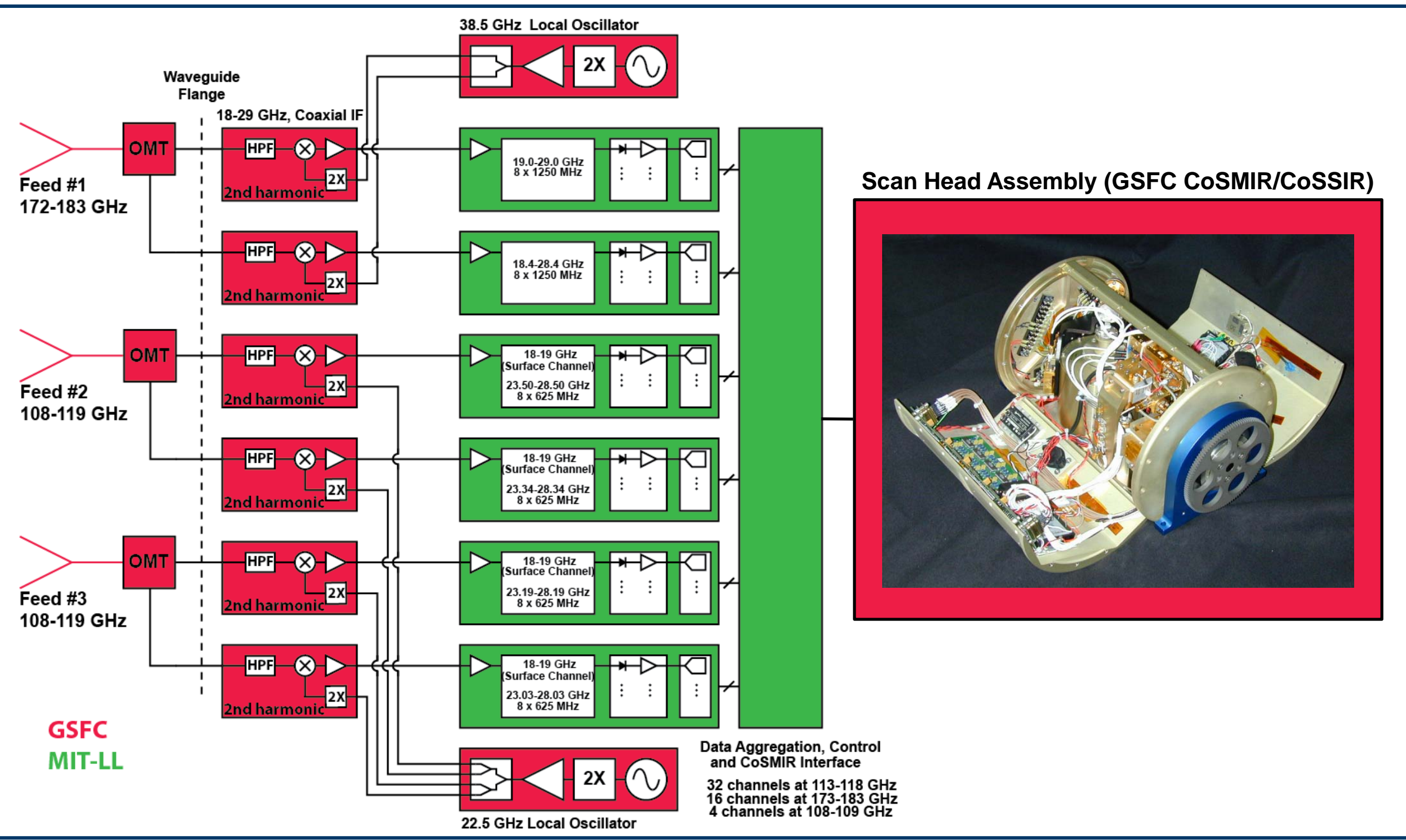




\section{HyMAS (9-channel) IF Frequency Plan}

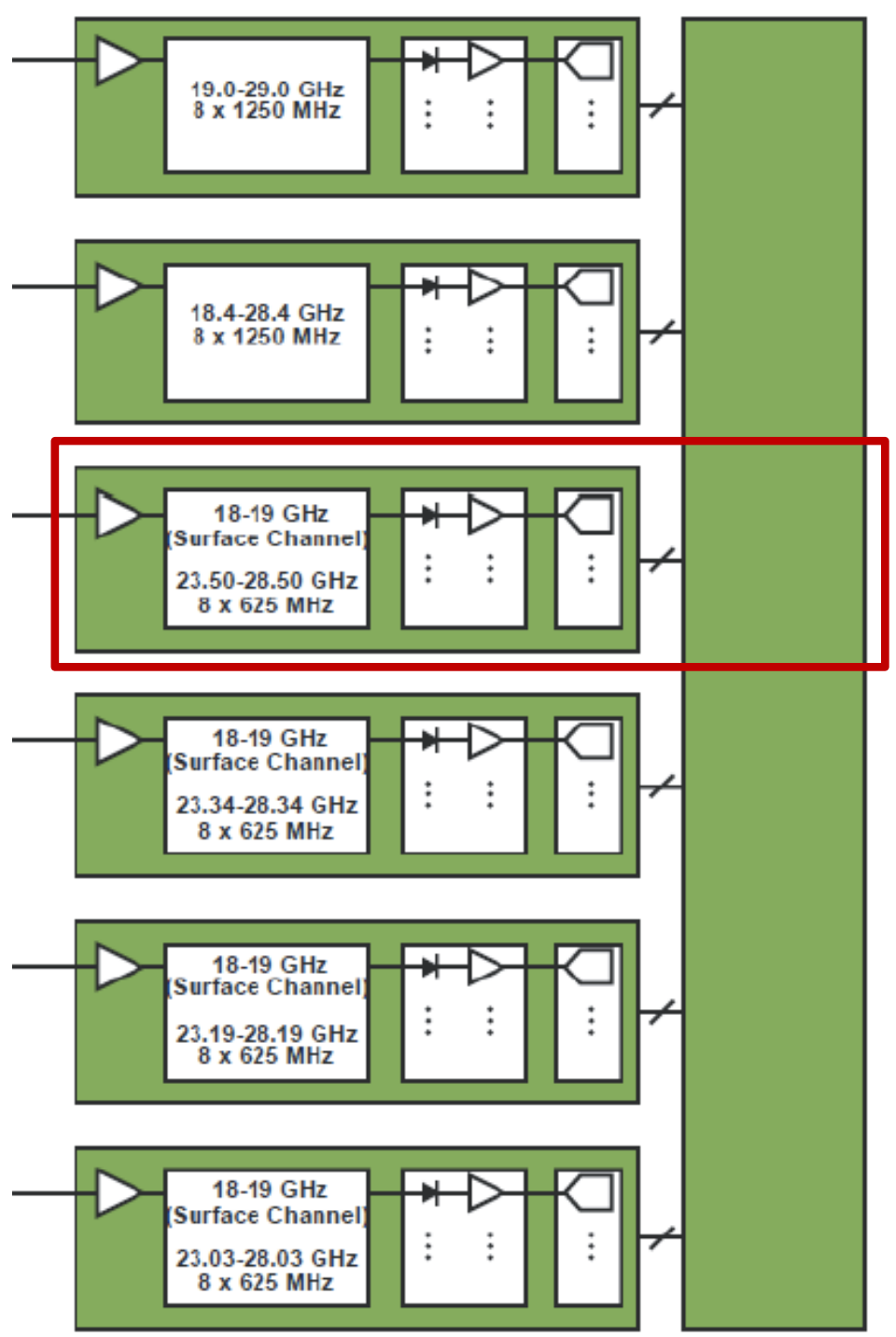




\section{IF Processor Description}

- K-connector (18-29 GHz) input from RF front-end

- Two IF amplifiers (18-29 GHz)

- Buffered with attenuators for gain adjustment and matching at IF input/output

- Provides termination for RF front-end output and multiplexer input

- Nominally $3 \mathrm{~dB}$ at input/output, " $0 \mathrm{~dB}$ " in between stages

- Multiplexer channelizes IF band

- Detectors detect power at output of each channel

- Op-amp fed by detectors, drives ADC

- Microcontroller sequences data flow 


\section{HyMAS - IF Processor}

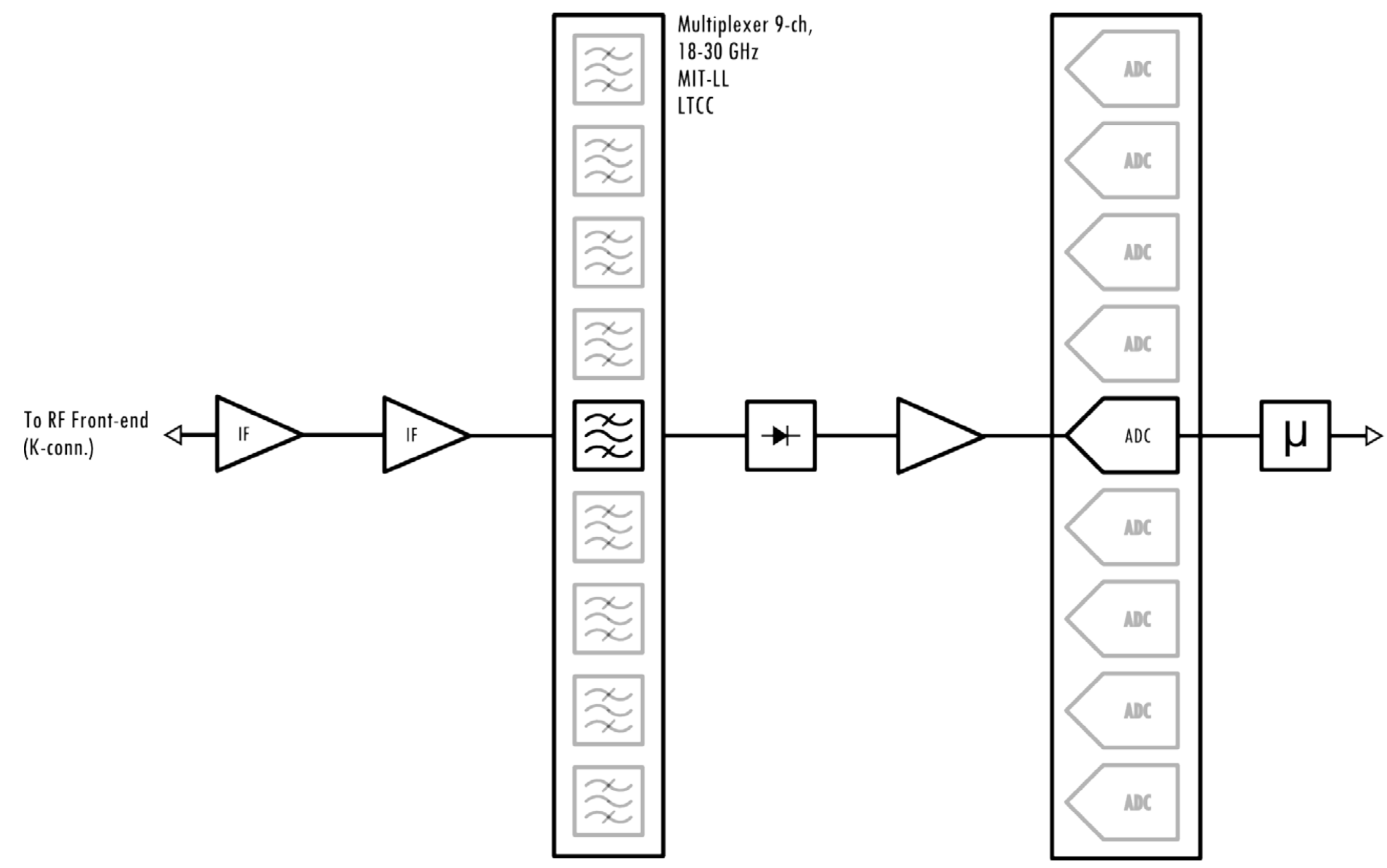




\section{IF Multiplexer}

- Single port feeds 9-channels through a corporate feed power splitting network

- Reduces interaction among contiguous channels

- Low-risk for initial demonstration

- IF channel filters are LTCC-based substrate integrated waveguide (SIW) cavity types

- High unloaded $Q$ resonators (500+) in small volume for low insertion loss and sharp filter skirts

- Probe/bond pads for S-parameter testing and assembly

- First 9-channel design completed and in fabrication

- Omega Micro Technology (DuPont 9K7), expect parts in 9/2012 


\section{HyMAS LTCC SIW Filters}

- Substrate Integrated Waveguide (SIW) filters offer lower insertion loss and better filter shape factor than stripline interdigital filters due to their higher $Q(>500)$ resonators

- Filters are realized in two-layer LTCC stack with via "fences" creating the waveguide side walls

- Via "posts" control coupling in between resonator cavities
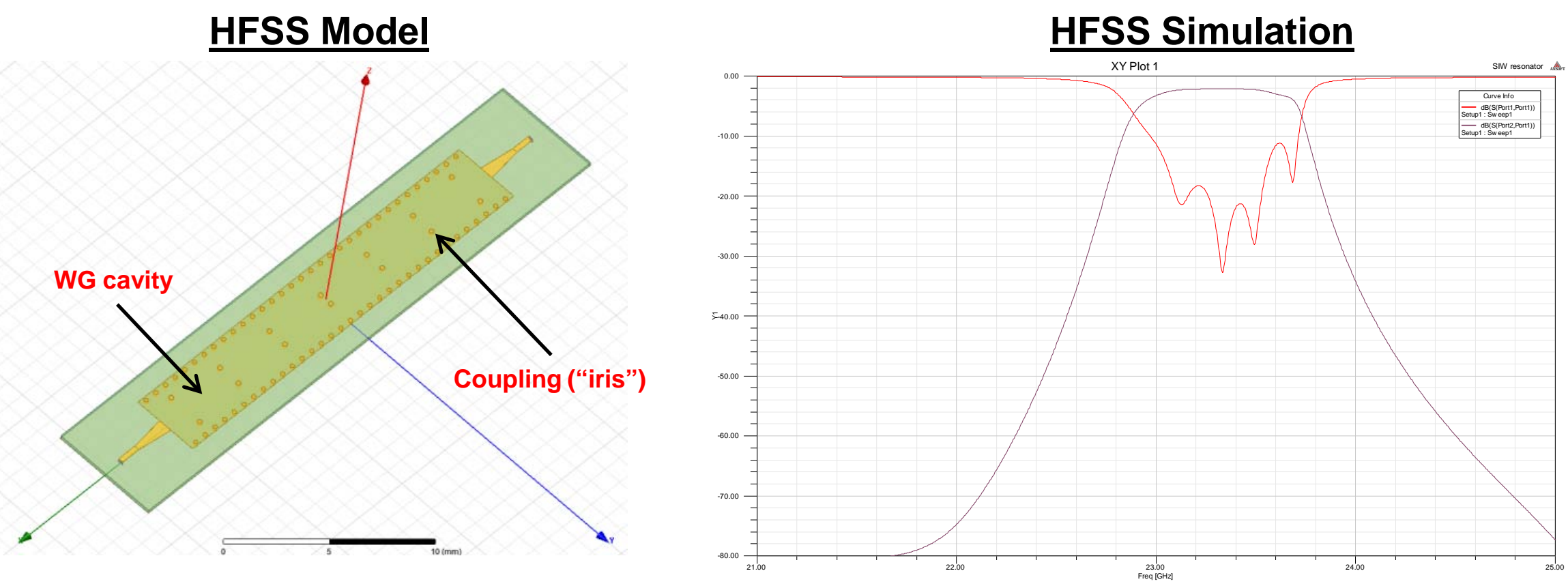


\section{IF Channel 1 (HFSS)}

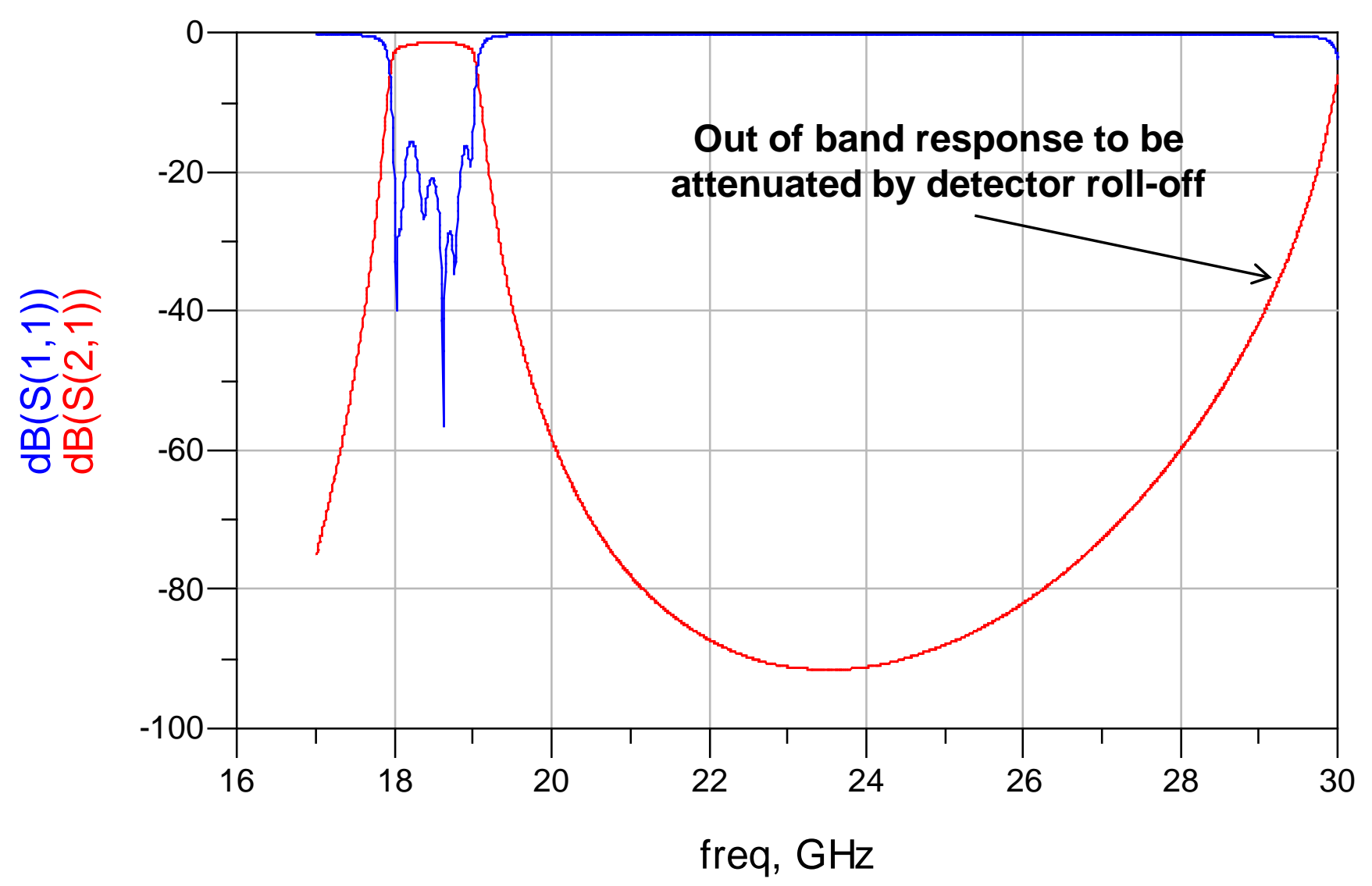




\section{IF Channel 2 (HFSS)}

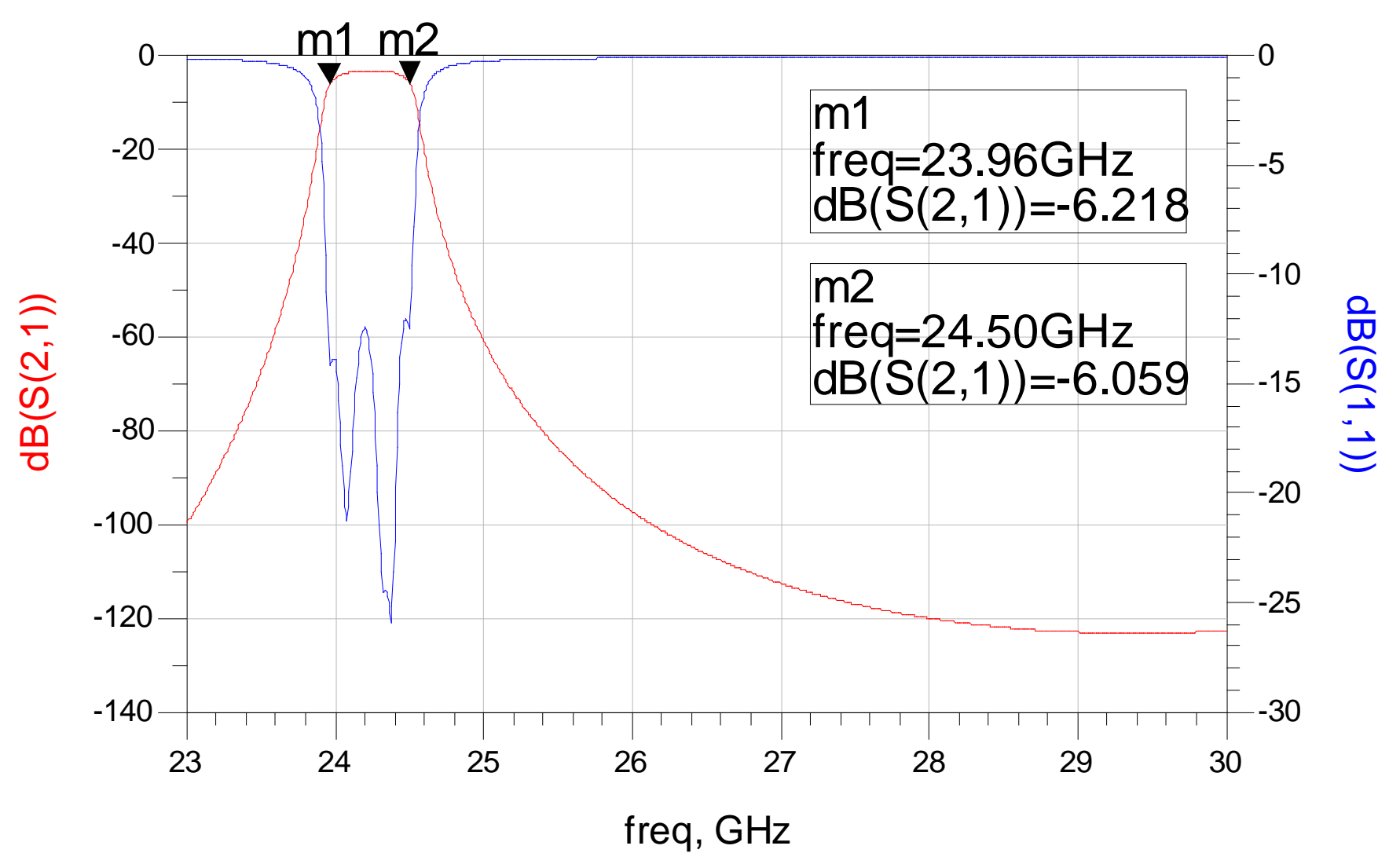




\section{IF Channel 3 (HFSS)}

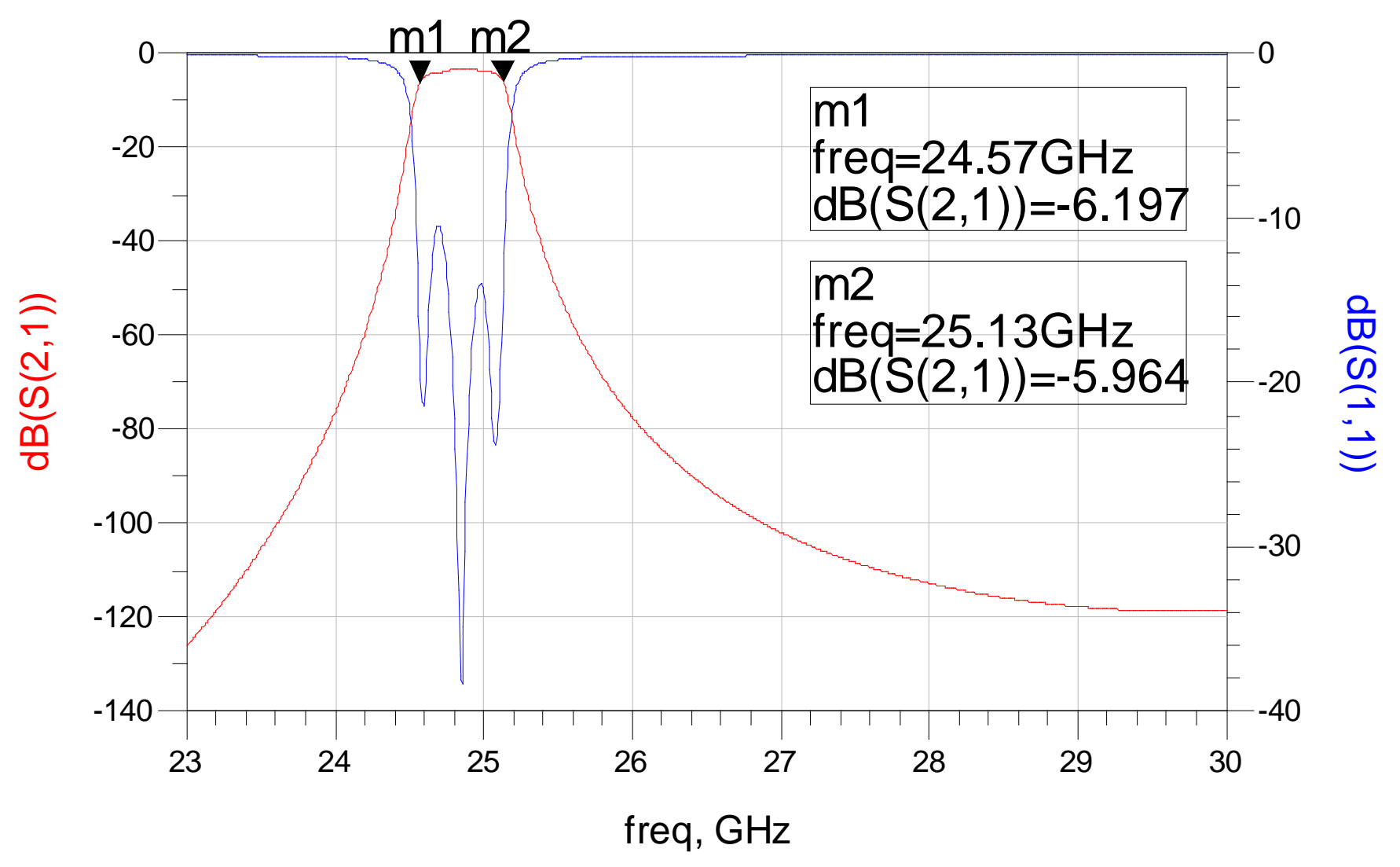




\section{IF Channel 4 (HFSS)}

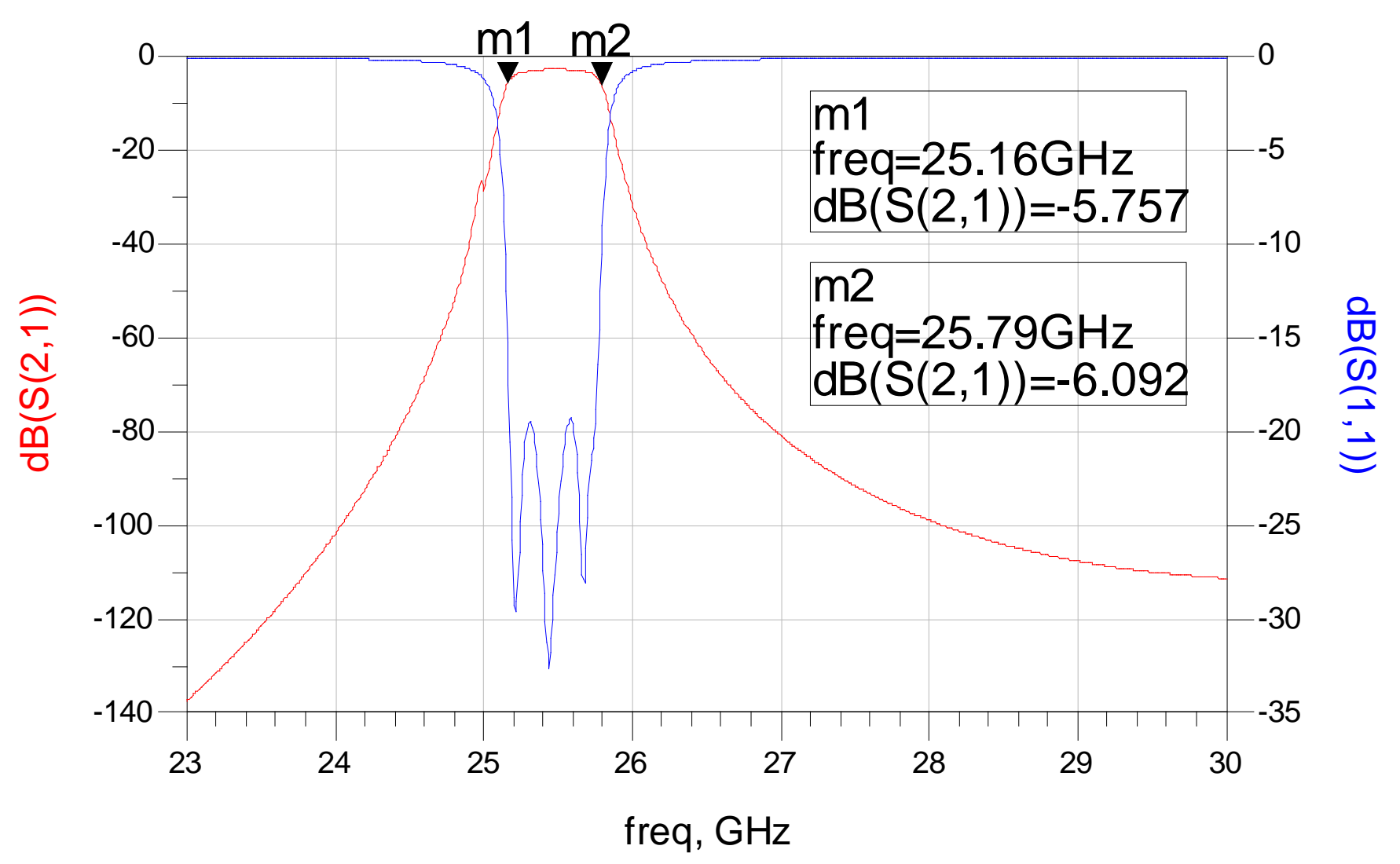




\section{IF Channel 5 (HFSS)}

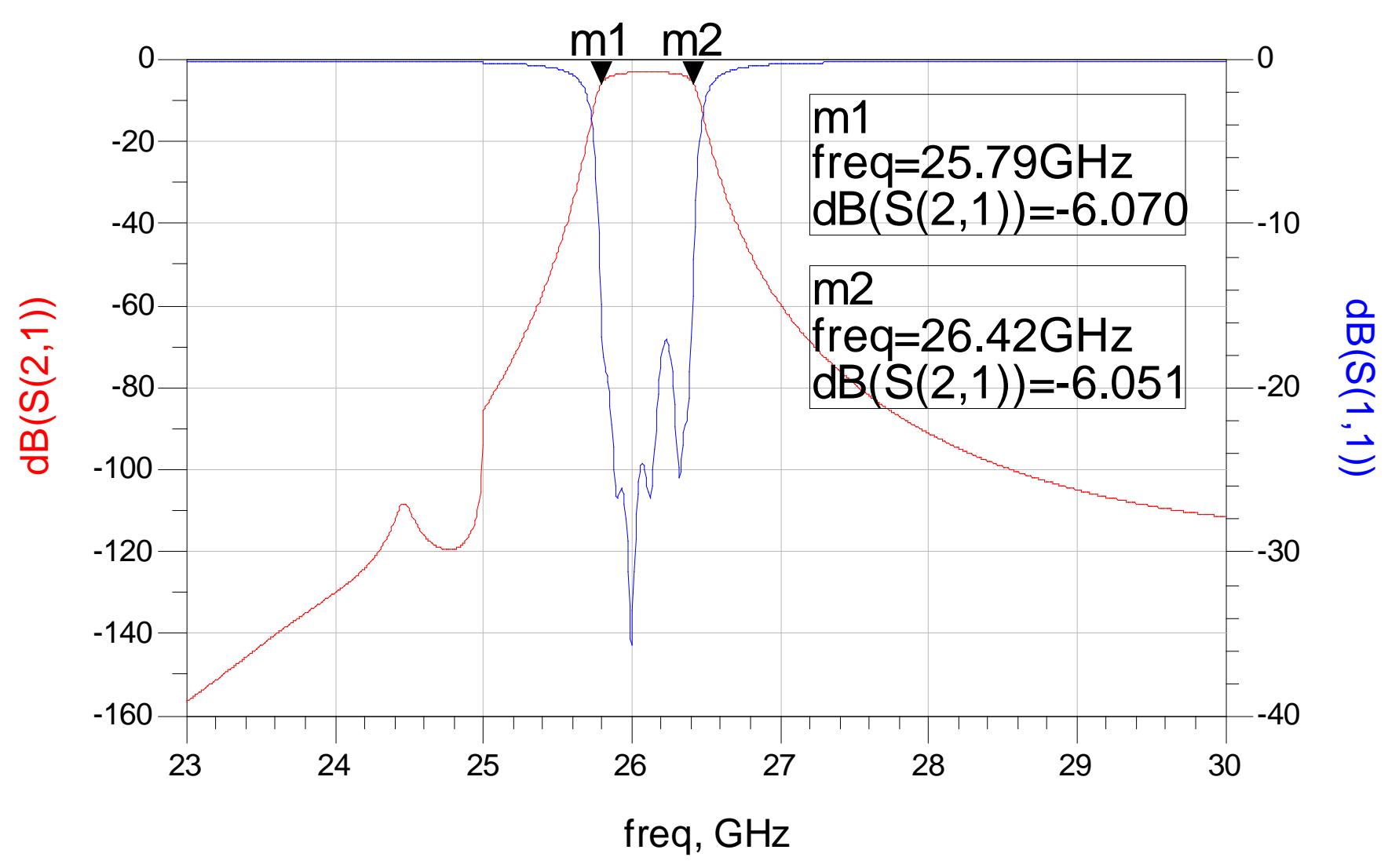




\section{IF Channel 6 (HFSS)}

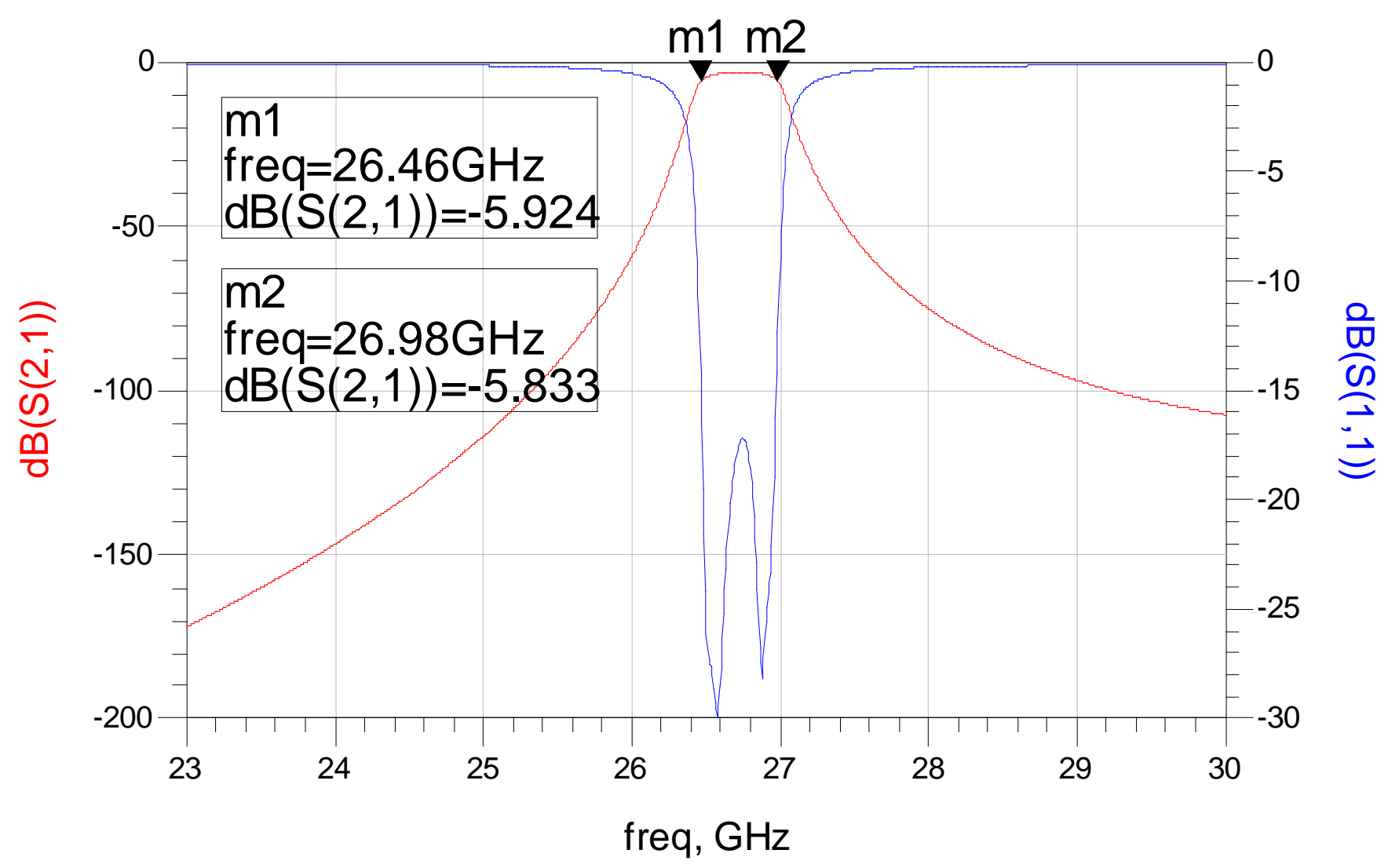




\section{IF Channel 7 (HFSS)}

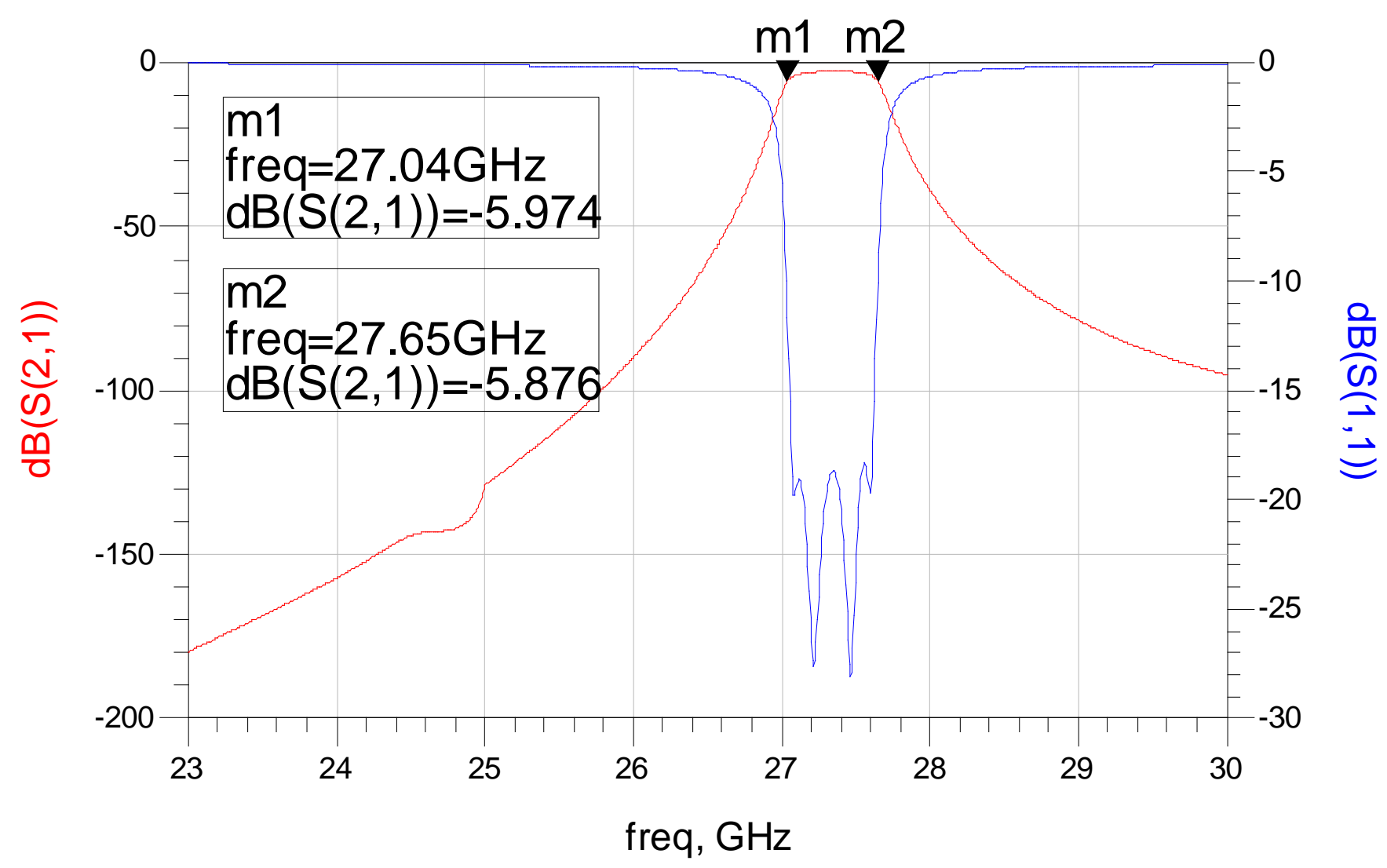




\section{IF Channel 8 (HFSS)}

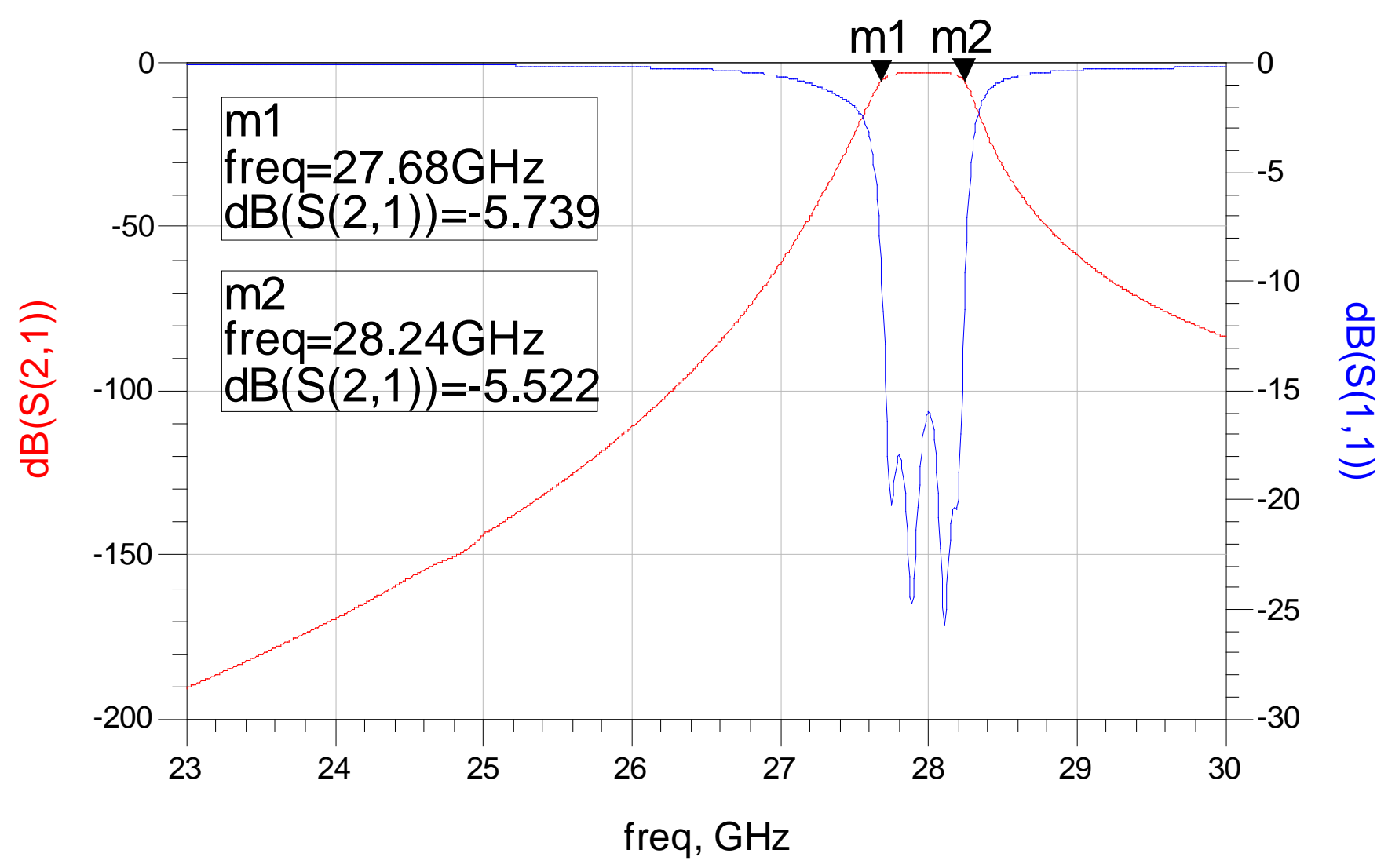




\section{IF Channel 9 (HFSS)}

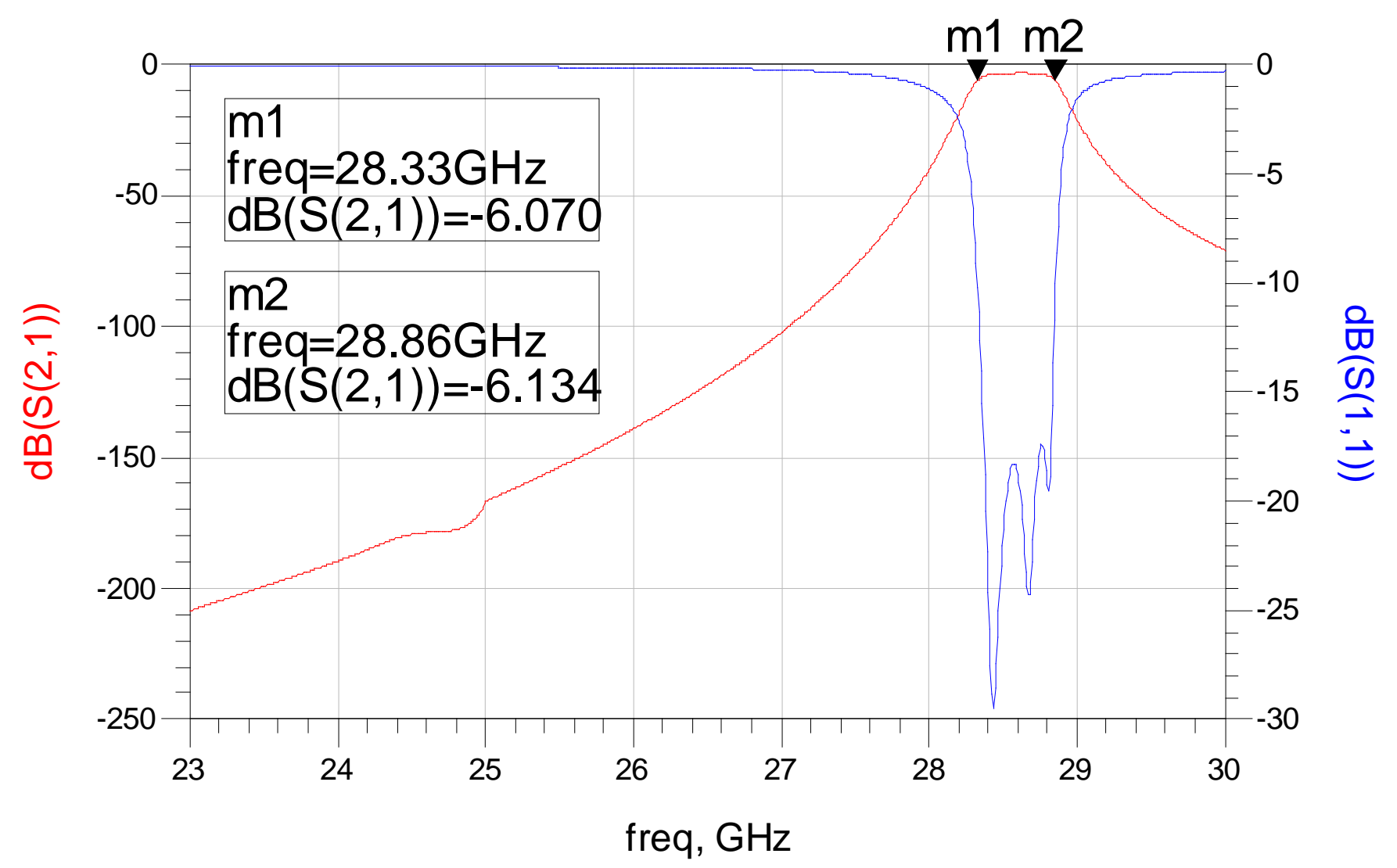




\section{IF Processor Form Factor 1 Horizontal Resonators}

Top View: 8/9-channel Panel

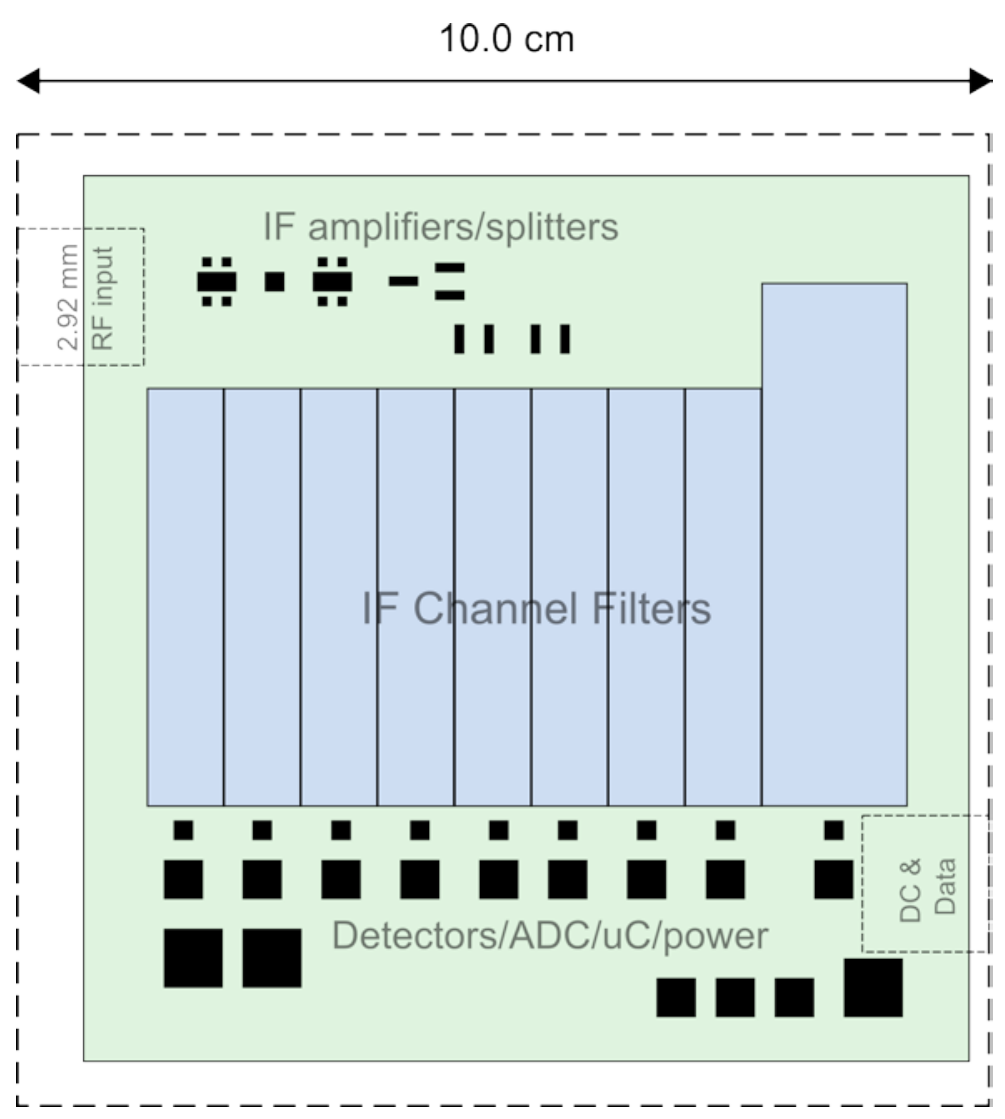

Side View: 52-ch IF Processor

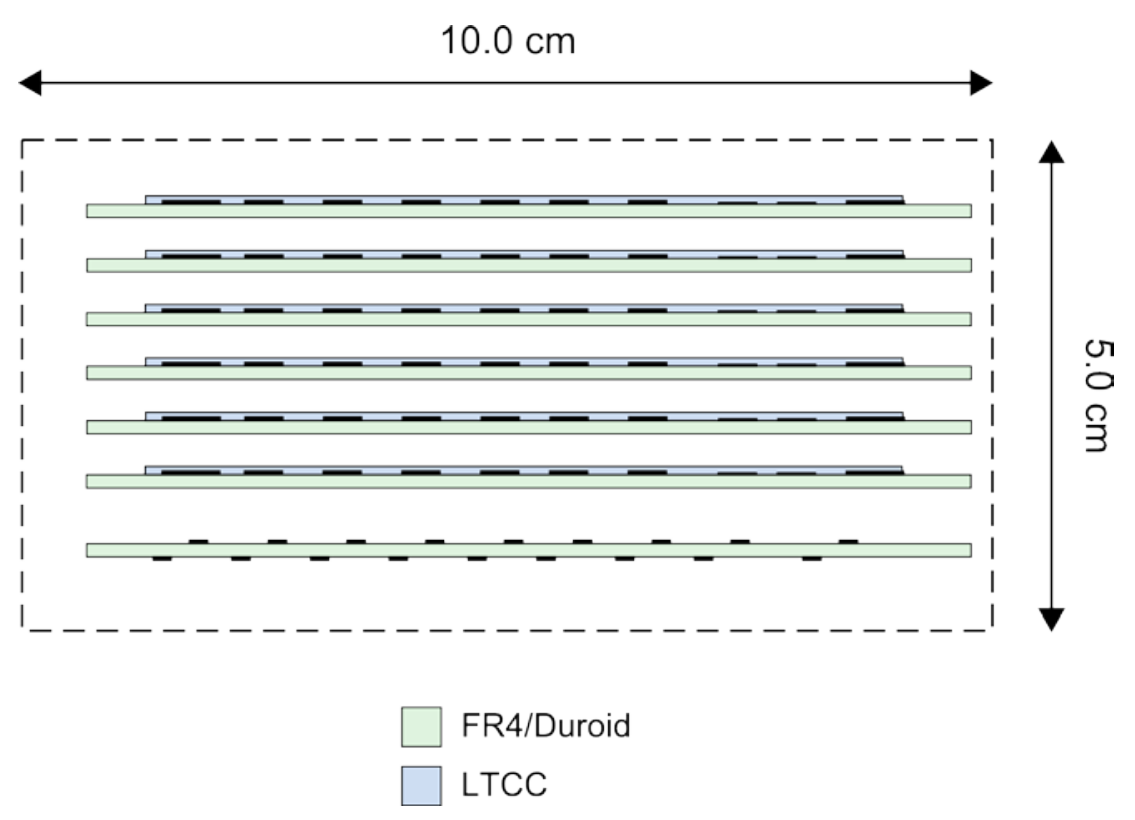


 Horizontal+Vertical (Stacked) Resonators}

Top View: 26-channel Panel

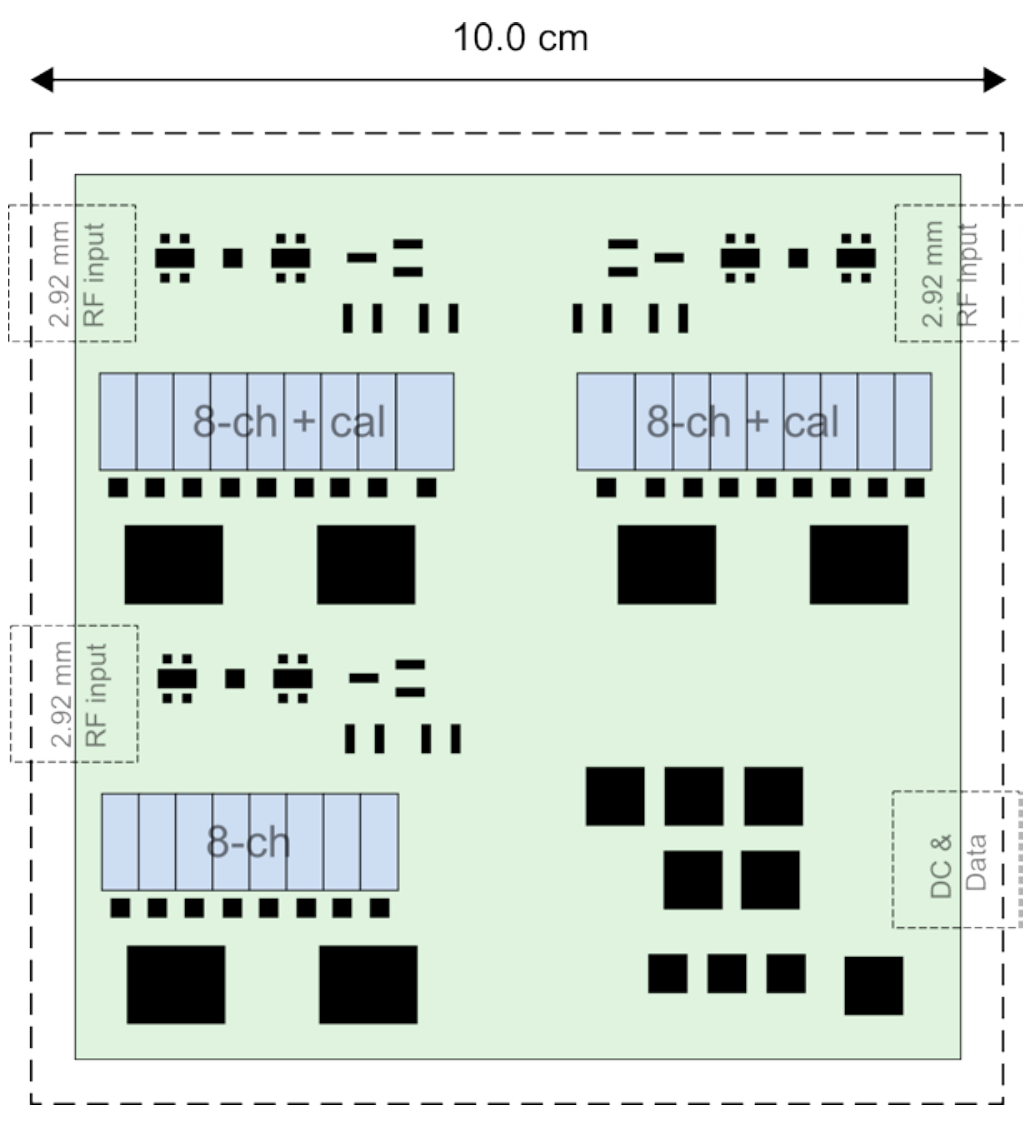

Side View: 52-ch IF Processor

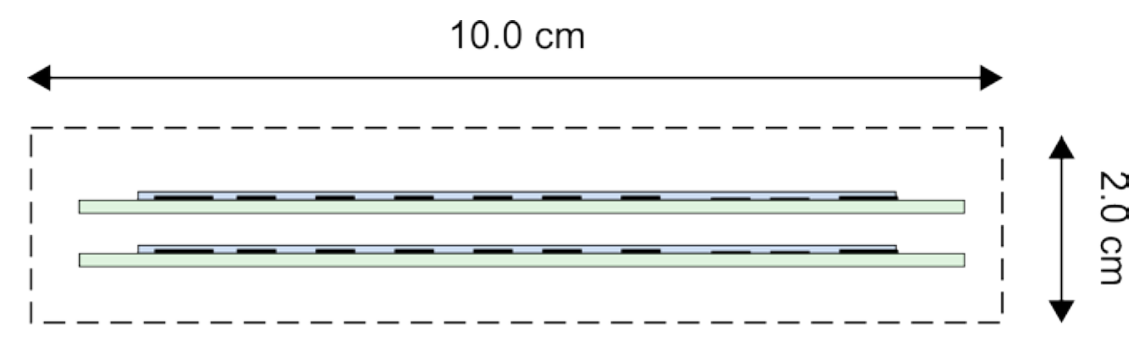

\section{FR4/Duroid \\ LTCC}


Top View: 52-channel Panel

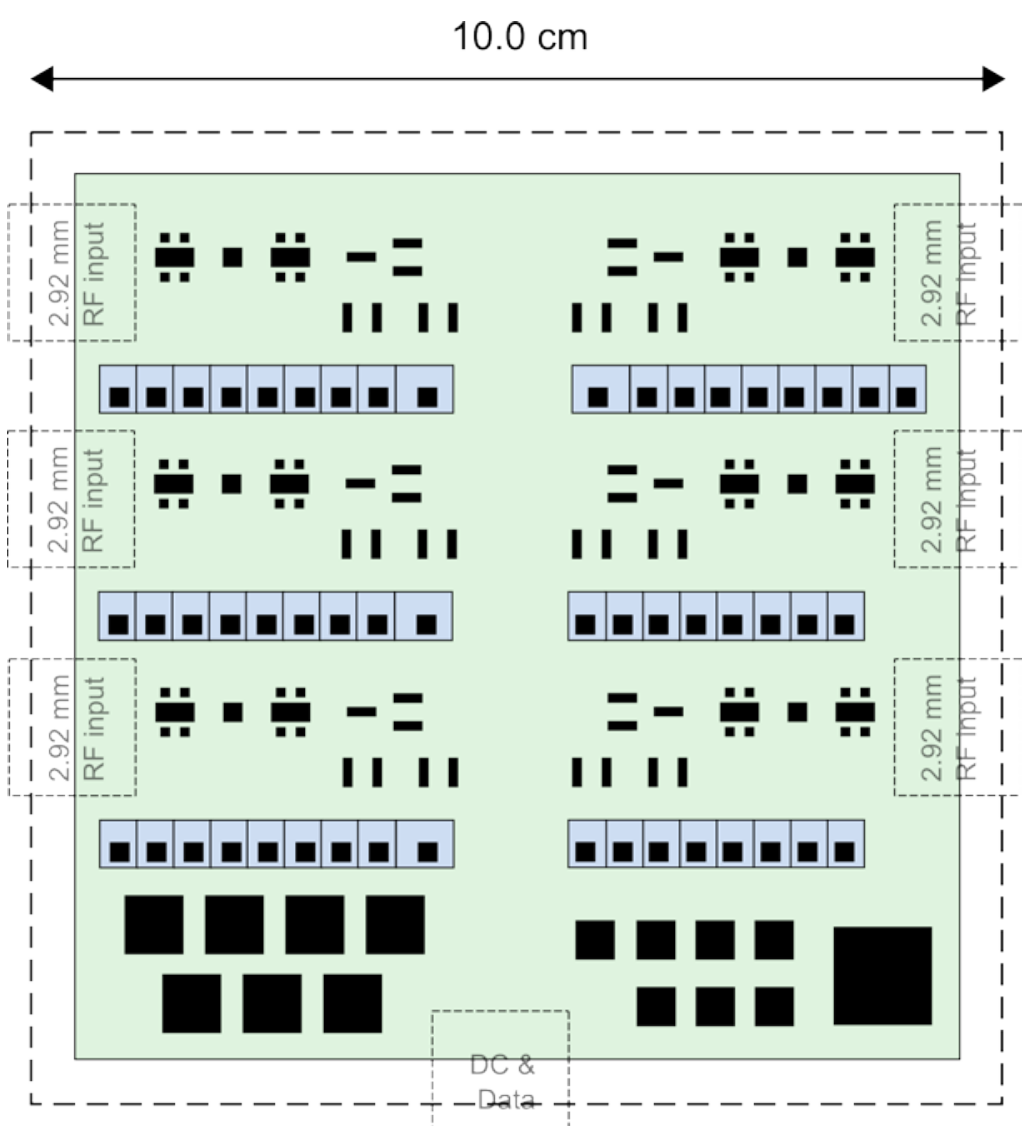

Side View: 52-ch IF Processor

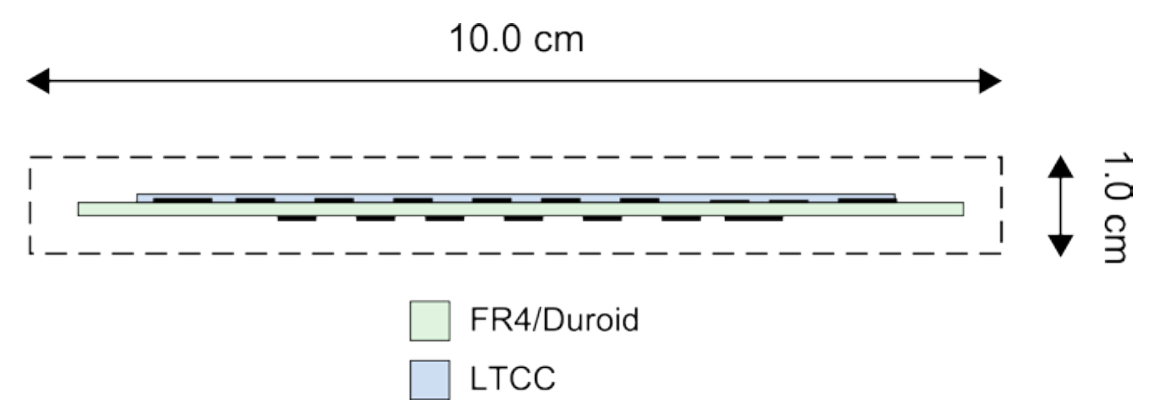




\section{Summary}

- Hyperspectral microwave sensors could change the landscape of atmospheric sounding for both LEO and GEO systems.

- An intermediate frequency processor fabricated in LTCC technology is a key innovation enabling ultracompact microwave radiometry in a variety of applications with severe constraints on size, weight, and power.

- Fabrication and testing of the hyperspectral microwave receiver subsystem will occur in 2012/2013 with airborne validation in 2014/2015. 


\section{Backup}




\section{CoSMIR/CoSSIR Scan Head}

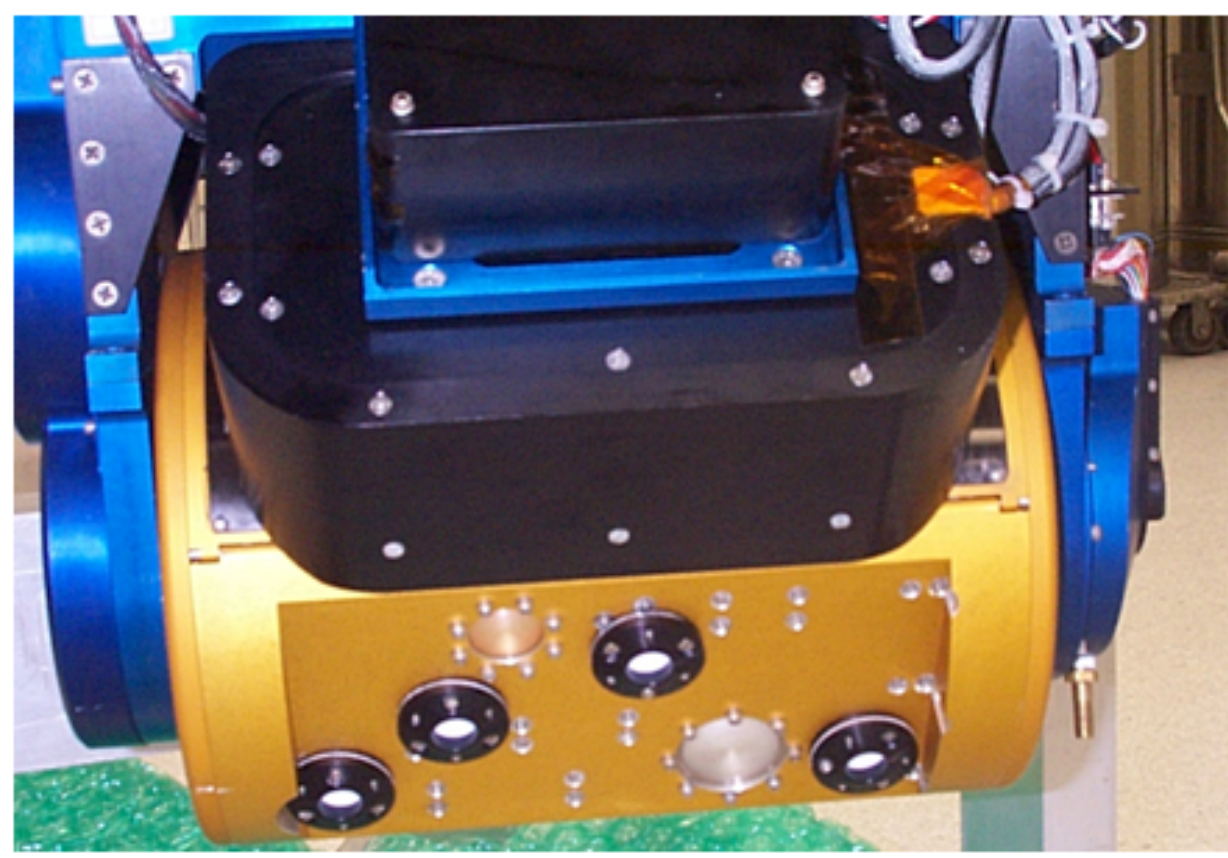

The scan head provides calibration and control infrastructure and rotates in azimuth and elevation. CoSSIR is shown in the photo at left.

A compact drum houses the radiometer electronics and rotates relative to the scan head

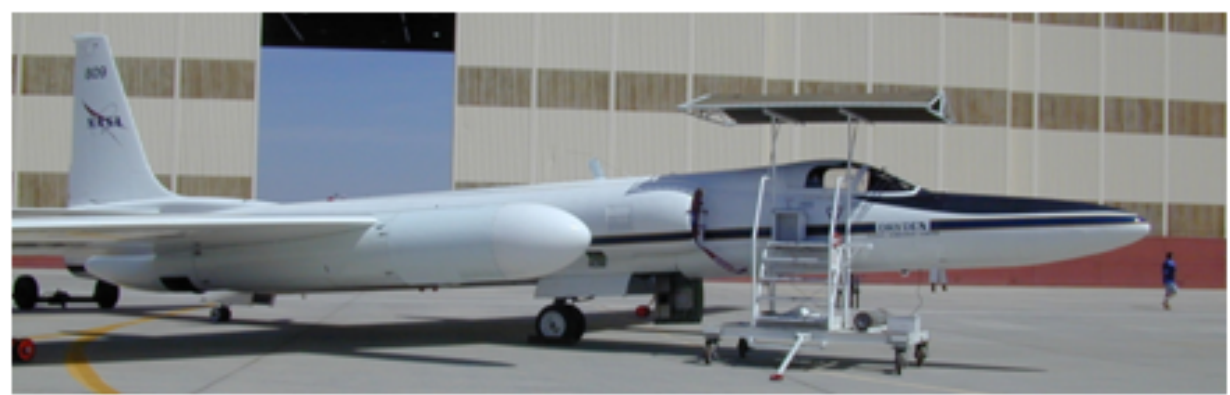

Flights on the ER-2 have produced many hours of highquality radiometric data 


\section{Frequency Plan}

\section{Example: 36 Channels near the 118.75-GHz oxygen line}

\begin{tabular}{|c|c|c|c|c|}
\hline Channel \# & Left edge & Center & Right edge & Bandwidth \\
\hline 1 & 108.0000 & 108.5000 & 109.0000 & 1.0000 \\
\hline 2 & 113.9135 & 114.2260 & 114.5385 & 0.625 \\
\hline 3 & 114.5375 & 114.8500 & 115.1625 & 0.625 \\
\hline 4 & 115.1615 & 115.4740 & 115.7865 & 0.625 \\
\hline 5 & 115.7855 & 116.0980 & 116.4105 & 0.625 \\
\hline 6 & 116.4095 & 116.7220 & 117.0345 & 0.625 \\
\hline 7 & 117.0335 & 117.3460 & 117.6585 & 0.625 \\
\hline 8 & 117.6575 & 117.9700 & 118.2825 & 0.625 \\
\hline 9 & 118.2815 & 118.5940 & 118.9065 & 0.625 \\
\hline
\end{tabular}

Channels 2-9 above are shifted by 156.25 MHz per band

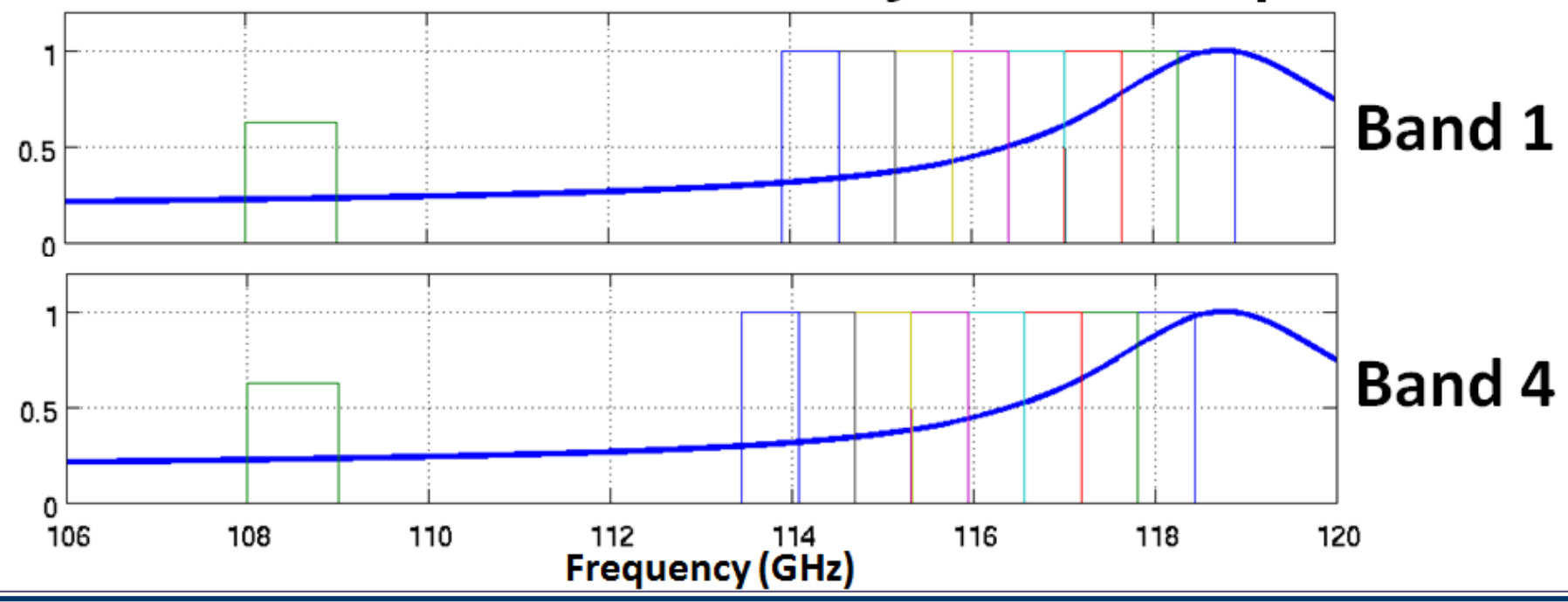

